\title{
ORIGINAL ARTICLE Comprehensive Approach to Lower Blood Pressure (CALM-BP): a randomized controlled trial of a multifactorial lifestyle intervention
}

\author{
A Ziv ${ }^{1}$, O Vogel ${ }^{1}$, D Keret ${ }^{1}$, S Pintov ${ }^{2}$, E Bodenstein ${ }^{1}$, K Wolkomir $^{1}$, K Doenyas $^{3,4}$, Y Mirovski $^{1}$ and S Efrati ${ }^{3,4}$
}

\begin{abstract}
Complementary medicine advocates the use of a multifactorial approach to address the varied aspects of hypertension. The aim of this study was to compare the blood pressure (BP) effect and medication use of a novel Comprehensive Approach to Lowering Measured Blood Pressure (CALM-BP), based on complementary medicine principles, with the standard recommended Dietary Approach to Stop Hypertension (DASH). A total of 113 patients treated with antihypertensive drugs were randomly assigned to either CALM-BP treatment (consisting of rice diet, walks, yoga, relaxation and stress management) or to a DASH + exercise control group (consisting of DASH and walks). Ambulatory 24-h and home BP were monitored over a 16-week programme, followed by 6 months of maintenance period. Medications were reduced if systolic BP dropped below $110 \mathrm{~mm} \mathrm{Hg}$ accompanied by symptoms. In addition to BP reduction, medications were reduced because of symptomatic hypotension in $70.7 \%$ of the CALM-BP group compared with $32.7 \%$ in the DASH group, $P<0.0001$. After 6 months, medication status was not altered in the majority of individuals. Significant reductions in body mass index, cholesterol and improved quality-of-life scores were observed only in the CALM-BP group. Lifestyle and diet modifications based on complementary medicine principles are highly effective with respect to $\mathrm{BP}$ control, medication use and cardiovascular risk factors.
\end{abstract}

Journal of Human Hypertension (2013) 27, 594-600; doi:10.1038/jhh.2013.29; published online 18 April 2013

Keywords: blood pressure; diet; lifestyle; stress; quality of life

\section{INTRODUCTION}

Nutritional, physical and psychosocial factors influence blood pressure (BP), and management of these factors has been shown to reduce BP in nonpharmacological, interventional clinical trials. ${ }^{1-8}$ The Seventh Report of the Joint National Committee on Prevention, Detection, Evaluation, and Treatment of High Blood Pressure (JNC-VII) emphasizes the benefit of combining several lifestyle modifications for BP control. ${ }^{9}$ In interventions such as Dietary Approach to Stop Hypertension (DASH) trials, BP reduction was similar in magnitude to drug therapy. ${ }^{10}$

Complementary medicine advocates the use of a multifactorial treatment approach to address the varied aspects of hypertension. These measures include a whole-grain rice diet, stress management, controlled diaphragmatic breathing, yoga, qigong and exercise. ${ }^{11-21}$ An assessment of a multifactorial treatment approach for BP control has never been conducted in a controlled clinical trial.

Comprehensive Approach to Lower Measured Blood Pressure (CALM-BP) is a multifactorial programme for BP control based on complementary medicine principles. The interventional approach in this study was aimed to educate participants to achieve a healthy lifestyle by establishing a home cooking routine that is based on healthy food consumption choices, to establish a physical exercise routine and to develop stress management coping skills. The objective of this study was to compare the effect of CALM-BP with the standard recommended DASH plus exercise intervention on $\mathrm{BP}$, medication use and cardiovascular risk factors in a hypertensive population treated with at least one BP-lowering drug.

\section{MATERIALS AND METHODS}

Trial conduct

The study was carried out at the Department of Integrated Medicine (Shiram) and the Research and Development Unit of Assaf Harofeh Medical Center, Israel. The institutional review board approved the protocol and all patients signed an informed consent before inclusion in the study. Participants were recruited from the community and from the medical centre cohort of patients. Advertisements were posted in the local newspapers and on the medical center website.

\section{Participants and group allocation}

Eligible participants were adults aged 22-75 years with mean systolic and diastolic BP of $120-180$ and $70-100 \mathrm{~mm} \mathrm{Hg}$, respectively, as recorded in an office visit measurement, treated with at least one antihypertensive drug 3 months before inclusion in the study. Other criteria were willingness to complete all data collection materials and to sign an informed consent form. Excluded were individuals with body mass index $>35 \mathrm{~kg} \mathrm{~m}^{-2}$, any cardiovascular event within 6 months before trial inclusion, inability to walk independently, insulin-dependent diabetes mellitus with $\mathrm{HbA} 1 \mathrm{C} \geqslant 7.5$, inflammatory bowel disease, known lifethreatening malignancy, pregnancy or lactation, consumption of more than 20 alcoholic beverages per week and an intention to change smoking habits.

${ }^{1}$ Shiram Integrated Medicine Unit, Assaf Harofeh Medical Center, Zerifin, Israel; ${ }^{2}$ The Medical School for International Health, Faculty of Health Sciences, Ben Gurion University of the Negev, Beer-Sheva, Israel; ${ }^{3}$ Division of Nephrology, Assaf Harofeh Medical Center, Zerifin, Israel and ${ }^{4}$ Research and Development Unit, Assaf Harofeh Medical Center, Zerifin, Israel. Correspondence: Dr S Efrati, Research and Development Unit, Assaf Harofeh Medical Center, Zerifin 70300, Israel. 
Participants were randomized to either CALM-BP or to DASH plus exercise control group over a period of 16 weeks. Patient follow-up continued for additional 6 months after the 16-week intervention period.

\section{Outcomes}

Participants were invited to the research centre outpatient clinic for a medical interview, complete physical examination and blood sampling. The 24-h ambulatory BP measurements were taken at the beginning and the end of the 16-week intervention period (90207 ABP monitors, Spacelabs Healthcare, Issaquah, WA, USA). BP measurements were taken by participants at home (Omron M2 blood pressure monitoring device, cuff size $22-32 \mathrm{~cm}$; Omron Healthcare Co., Ltd, Kyoto, Japan) three times a day, three measurements each time, on 2 consecutive days before the weekly clinic visit, and on the same weekdays during the follow-up period. Participants were instructed to measure BP after resting for $5 \mathrm{~min}$ in a seated position with the arm at chest level. The hand that presented the higher BP reading during screening was selected for all follow-up measurements. Home BP readings were recorded as the mean of second and third measurements on a specific form that was collected by the trial personnel at each visit and was sent by electronic mail during the follow-up period. Life quality Short Form 36 (SF36) questionnaires ${ }^{22}$ were filled and fasting blood samples were obtained the beginning and the end of the 16-week period.

Intervention: weekly sessions over a period of 4 months

Physical exercise. Participants, in both arms of the study (CALM-BP and $\mathrm{DASH}+$ exercise), attended a 45 -min group walk led by a qualified trainer to achieve $60-75 \%$ of the maximal recommended heart rate according to age, and were asked to walk at home similarly at least three additional times a week.

Dietary education. A weekly lecture focussed on conscious grocery shopping and healthful home cooking. The DASH group dietary plan was presented by a qualified nutritionist. Instructions were based on the new DASH eating plan. $^{23}$ The CALM-BP group dietary plan was based on naturopathic whole grain rice. In comparison with the DASH diet, the ricebased diet was initiated with a lower percentages of protein, lower percentages of fat and higher potassium. Adequate amounts of all the nutrients were gradually added to achieve a balanced, mostly vegetarian diet. The recommended dietary nutritional composition is summarized in Table 1.

Self-prepared group meal. In both arms of the study, weekly sessions included a communal meal prepared by participants according to the group eating plan. A list of specific food dishes for each participant was allocated in advance for each session.

Table 1. Recommended dietary nutritional composition in the different study groups

\begin{tabular}{|c|c|c|}
\hline & CALM-BP & $D A S H$ \\
\hline Total fat, $\%^{\mathrm{a}}$ & 13.1 & 27 \\
\hline Saturated fat, $\%^{\mathrm{a}}$ & 1.7 & 6 \\
\hline Protein, $\%^{\mathrm{a}}$ & 7.3 & 18 \\
\hline Carbohydrate, $\%^{\mathrm{a}}$ & 77.9 & 55 \\
\hline Cholesterol, mg & 0.0 & 150 \\
\hline Sodium, mg & 1511 & 2300 \\
\hline Potassium, mg & 7282 & 4700 \\
\hline Calcium, mg & 1136 & 1250 \\
\hline Magnesium, mg & 575 & 500 \\
\hline Fibre, $\mathrm{g}$ & 52 & 30 \\
\hline Calories, kcal day ${ }^{-1}$ & 2145 & 2100 \\
\hline
\end{tabular}

Abbreviations: CALM-BP, Comprehensive Approach to Lowering Measured Blood Pressure; DASH, Dietary Approach to Stop Hypertension. Values represent the mean recommended dietary plan as noted in the participants' nutritional manual and as prepared in weekly group meal. CALM-B is based on complementary medicine principles. Mid programme (weeks 6-7) values are presented. DASH, is according to the US Department of Health and Human Services, National Institute of Health, National Heart, Lung, and Blood Institute. Percent of total daily calories.
Relaxation and stress management. Only members of the CALM-BP group attended relaxation and stress management intervention that included a weekly $1 \mathrm{~h}$ relaxation session of yoga and qigong movements, breathing and meditation and a weekly group support counseling meeting that focussed on stress management. A 10-min qigong guided imagery audio $C D$ was distributed for daily use.

Adherence evaluation. All participants had to fill adherence questionnaires at week 4 and week 10 . These questionnaires included quantified questions regarding food consumption, exercise frequency and intensity and home relaxation sessions.

\section{Follow-up period}

In both arms of the study, the 6-month follow-up period began when the 16-week intervention ended. Both groups attended a monthly $2 \mathrm{~h}$ lifestyle maintenance session that included staff monitoring of BP and medication use, a group discussion with individual problem solving and a group meal.

\section{Dose reduction or cessation of antihypertensive medication}

Drugs were reduced or discontinued during the study when the mean systolic BP was $<110 \mathrm{~mm} \mathrm{Hg}$ on two consecutive days in conjunction with symptoms of hypotension (weakness, dizziness, blurred vision or presyncope). Trial staff was available for contact at all times by telephone. The physician in charge of the study, a nephrologist, verified with each candidate that BP measuring was done adequately and that hypotensi on was also indicated by associated symptoms. The physician was blinded to the patient's group. Unless an individual patient's needs required otherwise, dose reduction or cessation was conducted according to medication class in the following order: diuretics first, $\beta$-blockers second, angiotensin-converting enzyme inhibitors third, calcium channel blockers fourth and angiotensin II receptor blockers last.

\section{Statistical analysis}

Numerical data were analysed and results are presented as mean s.d., whereas categorical results are presented as percentages. The differences between the two groups were examined with the independent $t$-test for numerical data. For the categorical data, the groups were compared by Fisher's exact test (two groups) or $\chi^{2}$-test ( $>2$ groups). The differences between the two groups in time to target (symptomatic BP reduction below $110 \mathrm{~mm} \mathrm{Hg}$ ) were analysed by the Kaplan-Meier method and log-rank test was used to assess the significance of difference between the two unadjusted survival curves. All statistical analyses were performed using SPSS statistical software, version 18.0 (Corporate headquarters, SPSS Inc., Chicago, IL, USA).

\section{RESULTS}

Participant characteristics and adherence

Initial screening involved 235 individuals of whom 113 were included in the study (Figure 1). The mean age was $57 \pm 9$ years, and mean body mass index was $29 \pm 4 \mathrm{~kg} \mathrm{~m}^{-2} ; 51 \%$ of the participants were women. Baseline ambulatory systolic and diastolic BP values were similar in both groups (Table 2). More participants in DASH group had hyperlipidaemia and were treated with lipid-lowering drugs. No other significant between-group differences were observed (Table 2).

The overall adherence rate was $95.5 \%$ at 4 months (100\% in the CALM-BP group and $90 \%$ in DASH group; Figure 1). Adherence at 10 months was $70 \%$ in the CALM-BP group and $30 \%$ in the DASH group.

\section{Change in BP and BP medication}

During the 16-week period, BP measurements $<110 \mathrm{~mm} \mathrm{Hg}$ accompanied by symptoms of hypotension were recorded on two consecutive days in 41 of 58 (70.7\%) participants in the CALMBP group compared with 18 of 55 (32.7\%) participants in the DASH group $(P<0.0001)$. BP reductions were observed mainly during the first 5 weeks in the CALM-BP group in comparison with a steady-reduction rate in the DASH group $(P<0.0001$; Figure 2$)$. For these participants, the dosage of the antihypertensive medication 


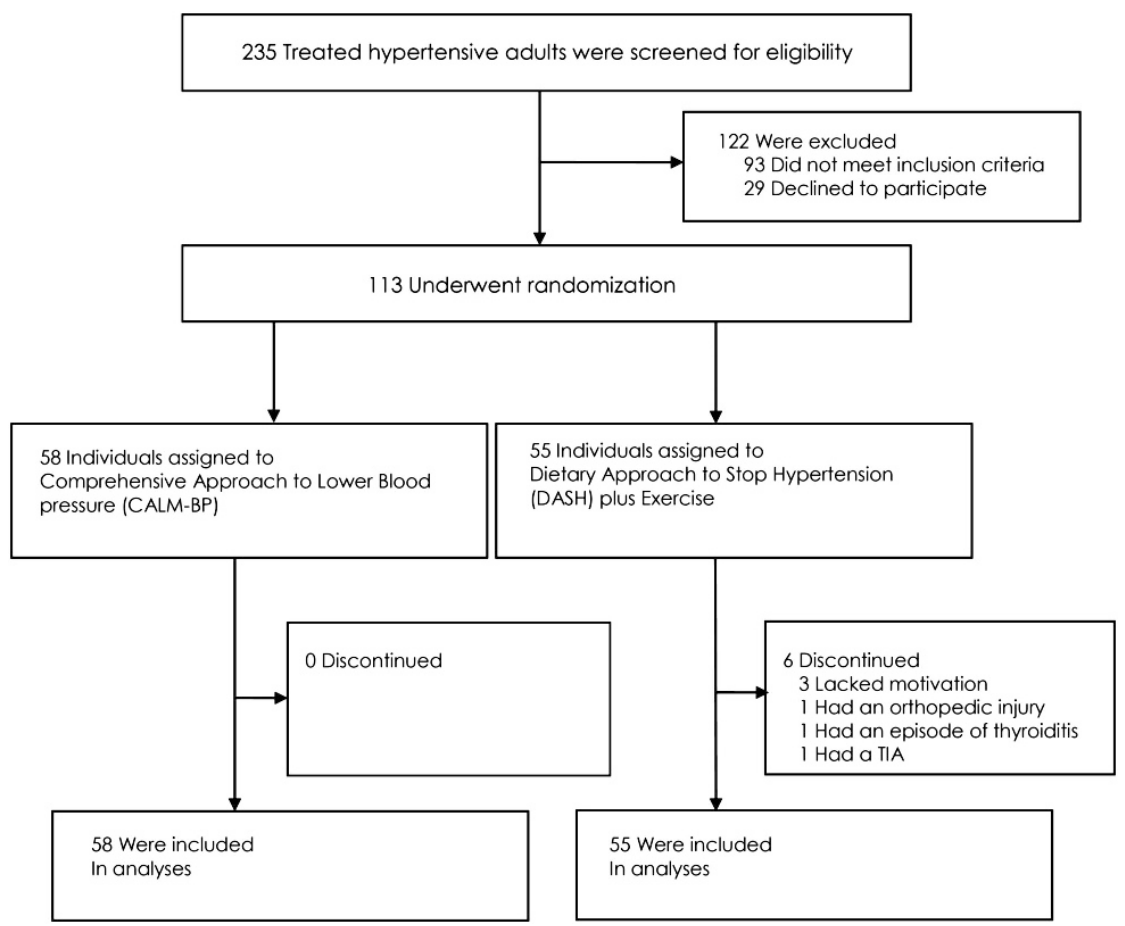

Figure 1. Screening, randomization and follow-up. CALM-BP: Comprehensive Approach to Lowering Measured Blood Pressure, based on complementary medicine principles. DASH: the standard recommended Dietary Approach to Stop Hypertension according to the US Department of Health and Human Services, National Institute of Health, National Heart, Lung, and Blood Institute.

Table 2. Baseline patient's characteristics

\begin{tabular}{|c|c|c|c|c|}
\hline & $C A L M-B P(\mathrm{n}=58)$ & $D A S H(\mathrm{n}=55)$ & All $(\mathrm{N}=113)$ & P-value \\
\hline Age, years (s.d.) & $57(8)$ & $58(9)$ & $57(9)$ & 0.67 \\
\hline Women, \% & 48 & 54 & 51 & 0.50 \\
\hline BMI, $\mathrm{kg} \mathrm{m}^{-2}$ (s.d.) & $30(4)$ & $29(4)$ & $29(4)$ & 0.78 \\
\hline Current smokers, \% & 10 & 2 & 6 & 0.83 \\
\hline Diabetes mellitus, \% & 9 & 9 & 9 & 0.95 \\
\hline CVA/TIA, \% & 0 & 1 & 1 & 0.30 \\
\hline IHD, \% & 2 & 10 & 5 & 0.08 \\
\hline CRF, \% & 4 & 6 & 5 & 0.62 \\
\hline Hyperlipidaemia, \% ${ }^{\mathrm{a}}$ & 31 & 52 & 42 & 0.02 \\
\hline Mean $24 \mathrm{~h}$ systolic blood pressure (s.d.) & $132(12)$ & $129(14)$ & $130(13)$ & 0.17 \\
\hline Mean $24 \mathrm{~h}$ diastolic blood pressure (s.d.) & $80(9)$ & $79(9)$ & $80(9)$ & 0.35 \\
\hline \multicolumn{5}{|l|}{ BP medication use, $\%^{\mathrm{b}}$} \\
\hline ACE & 48 & 55 & 51 & 0.44 \\
\hline ARB & 24 & 21 & 23 & 0.77 \\
\hline $\mathrm{CCB}$ & 37 & 41 & 39 & 0.59 \\
\hline$\beta$-Blockers & 47 & 51 & 49 & 0.64 \\
\hline$\alpha$-Blockers & 14 & 6 & 10 & 0.13 \\
\hline Diuretics & 47 & 47 & 47 & 0.93 \\
\hline Lipids medication use, $\%^{\mathrm{a}}$ & 26 & 56 & 41 & 0.01 \\
\hline
\end{tabular}

Abbreviations: ACE, angiotensin-converting inhibitor; ARB, angiotensin receptor blocker; BMI, body mass index; BP, blood pressure; CALM-BP, Comprehensive Approach to Lowering Measured Blood Pressure; CCB, calcium channel blockers; CRF, chronic renal failure; CVA, cerebrovascular accident, DASH, Dietary Approach to Stop Hypertension; IHD, ischaemic heart disease; TIA, transient ischaemic attack. CALM-BP is based on complementary medicine principles. DASH is according to the US Department of Health and Human Services, National Institute of Health, National Heart, Lung, and Blood Institute. ${ }^{a}$ Mean difference between groups with $P<0.05$. ${ }^{b}$ Combined therapy according to specific class: CCB, ARB and ACE.

was reduced or medications were stopped. The first drugs to be withdrawn according to the protocol were diuretic. Accordingly, diuretics were stopped in 19 of 27 (70.4\%) participants in the CALM-BP group compared with 8 of 26 (30.8\%) in the DASH group $(P=0.006)$.

The mean decrease in 24-h systolic and diastolic BP in each group, including the participants who had medication reduction (the mean decrease is after the medication reduction), was $4.33 / 3.07 \mathrm{~mm} \mathrm{Hg}$ in the CALM-BP group $(P=0.004 / P=0.003)$ and $4.0 / 1.9$ in the DASH group $(P=0.013 / P=0.06$, Table 3$)$. After medication step down, no significant net changes between groups were observed. After 6 months of follow-up, home BP measurements and medication status were unchanged in $86 \%$ of individuals in the DASH group and in $73 \%$ in the CALM-BP group. 
Biochemical and metabolic changes

The mean body mass index in the treatment group decreased by $2.42 \pm 2.6 \mathrm{~kg} \mathrm{~m}^{-2}$ compared with $0.17 \pm 2.9 \mathrm{~kg} \mathrm{~m}^{-2}$ in the DASH

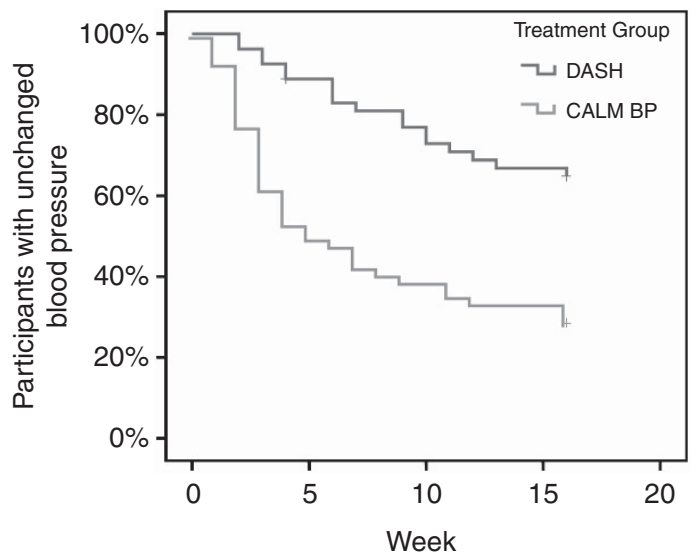

Figure 2. Time until blood pressure medication reduction during the intervention period. Antihypertensive medications were reduced or discontinued if the mean systolic blood pressure was $<110 \mathrm{~mm} \mathrm{Hg}$ on two consecutive days in conjunction with symptoms related to hypotension (weakness, dizziness, blurred vision or presyncope). CALM-BP: Comprehensive Approach to Lowering Measured Blood Pressure, based on complementary medicine principles. DASH: the standard recommended Dietary Approach to Stop Hypertension according to the US Department of Health and Human Services, National Institute of Health, National Heart, Lung, and Blood Institute. group, resulting in a net relative reduction of 2.25 (95\% confidence interval $(\mathrm{Cl})-3.3$ to $-1.1, P<0.0001)$. The average total cholesterol decrease in the CALM-BP group was $13.69 \pm$ $24.6 \mathrm{mg} \mathrm{dl}^{-1}, P<0.0001$, of which $9.58 \pm 21.4 \mathrm{mg} \mathrm{dl}^{-1}$ reduction was in low-density lipoprotein cholesterol, $P=0.002$, and $2.4 \pm$ $6.5 \mathrm{mg} \mathrm{dl}^{-1}$ in high-density lipoprotein cholesterol, $P=0.009$. No significant changes were observed in the DASH group (Table 3 ). Fasting blood glucose levels decreased by $10.59 \pm 17.7$, $P<0.0001 \mathrm{mg} \mathrm{dl}^{-1}$ in the CALM-BP group, and by $7.44 \pm 12.1$, $P<0.0001 \mathrm{mg} \mathrm{dl}^{-1}$ in the DASH group. The results are summarized in Table 3.

\section{Life quality}

CALM-BP group SF36 life quality increased in physical, mental and total scores, resulting in a net score improvement of $11.5(95 \% \mathrm{Cl}$ : 5-17, $P<0.001), 10.1$ (95\% Cl: 3.5-16.6, $P=0.003)$ and $10.9(95 \%$ Cl: 4.6-17.1, $P=0.001)$, respectively. No significant improvement in any of these parameters was observed in the DASH group (Table 3).

\section{Adverse events}

The most commonly reported adverse events in both groups included abdominal discomfort, weakness and headache. More participants in the CALM-BP group reported weakness $(17 ; 29.3 \%)$ when compared with the DASH group $(5 ; 9.1 \%, P=0.009$, Table 4). However, these complaints were transient, associated with low BP, and disappeared after reduction or discontinuation of medication.

\begin{tabular}{|c|c|c|c|c|c|c|c|c|}
\hline \multirow[t]{2}{*}{ Characteristic } & \multicolumn{4}{|c|}{$C A L M-B P$} & \multicolumn{4}{|c|}{ DASH } \\
\hline & Baseline & Follow-up & Change & P-value & Baseline & Follow-up & Change & P-value \\
\hline \multicolumn{9}{|l|}{ Physical characteristics } \\
\hline BMI & $30(40)$ & $28(4)$ & 2.4 & 0.00 & $29(4)$ & $29(5)$ & 0.17 & 0.70 \\
\hline Weight, kg & $87(13)$ & $80(11)$ & 7.2 & 0.00 & $81(11)$ & $80(13)$ & 0.5 & 0.68 \\
\hline \multicolumn{9}{|l|}{ Lipids, $m g d^{-1}$} \\
\hline Total cholesterol & $174(30)$ & $160(31)$ & 13.7 & 0.00 & $168(34)$ & $164(32)$ & 3.6 & 0.45 \\
\hline HDL-C & $48(13)$ & $46(13)$ & 2.4 & 0.01 & $53(15)$ & $52(13)$ & 1.0 & 0.31 \\
\hline LDL-C & $101(23)$ & $91(25)$ & 9.6 & 0.002 & $93(30)$ & $92(30)$ & 0.9 & 0.86 \\
\hline Triglycerides & $123(55)$ & $115(24)$ & 8.5 & 0.12 & $114(59)$ & $102(42)$ & 11.7 & 0.16 \\
\hline \multicolumn{9}{|l|}{ Blood chemistry } \\
\hline Glucose & $96(17)$ & $85(11)$ & 10.6 & 0.000 & $92(14)$ & $85(14)$ & 7.4 & 0.00 \\
\hline \multicolumn{9}{|l|}{ Life quality } \\
\hline SF36 physical & $71(17)$ & $79(16)$ & 8.0 & 0.001 & $76(14)$ & $73(18)$ & -3.5 & 0.09 \\
\hline SF36 mental & $70(18)$ & $79(13)$ & 9.1 & 0.001 & $77(15)$ & $76(15)$ & -1.0 & 0.64 \\
\hline SF36 total & $73(17)$ & $81(14)$ & 7.7 & 0.002 & 79 (14) & $76(17)$ & -3.2 & 0.12 \\
\hline \multicolumn{9}{|c|}{ Ambulatory blood pressure } \\
\hline 24-h mean SBP & $132(12)$ & $128(11)$ & $4.3(1)$ & 0.004 & $129(14)$ & $125(14)$ & $4(10)$ & 0.01 \\
\hline 24-h mean DBP & $80(9)$ & $77(8)$ & $3.1(3.07)$ & 0.003 & $79(9)$ & $76(7)$ & $1.9(6)$ & 0.06 \\
\hline Awake mean SBP & $136(12)$ & $129(11)$ & $6.2(10.3)$ & 0.004 & $133(14)$ & $128(13)$ & $5.4(13)$ & 0.04 \\
\hline Awake mean DBP & $84(9)$ & $80(8)$ & $3.8(8)$ & 0.021 & $82(7)$ & 79 (7) & $2.7(6)$ & 0.049 \\
\hline Asleep mean SBP & $122(23)$ & $119(26)$ & $3.0(18.8)$ & 0.521 & $120(22)$ & $117(22)$ & $3.8(10.7)$ & 0.47 \\
\hline Asleep mean DBP & $72(13)$ & $70(15)$ & $2.2(11.1)$ & 0.421 & $72(14)$ & $70(12)$ & $2.7(10)$ & 0.46 \\
\hline
\end{tabular}

Abbreviations: BMI, body mass index; CALM-BP, Comprehensive Approach to Lowering Measured Blood Pressure; DASH, Dietary Approach to Stop Hypertension; DBP, diastolic blood pressure; HDL-C, high-density lipoprotein cholesterol; LDL-C, low-density lipoprotein cholesterol; SBP, systolic blood pressure; SF36, Short Form 36. CALM-BP is based on complementary medicine principles. Mid programme (weeks 6-7) values are presented. DASH is according to the US Department of Health and Human Services, National Institute of Health, National Heart, Lung, and Blood Institute. Values are mean (s.d.). 
Table 4. Number (\%) of patients who reported adverse events

\begin{tabular}{lclc}
\hline & CALM-BP & DASH & P-value \\
\hline Abdominal discomfort & $6(10.3 \%)$ & $5(9.1 \%)$ & 1.000 \\
Diarrhoea & $3(5.2 \%)$ & $1(1.8 \%)$ & 0.619 \\
Constipation & $6(10.3 \%)$ & $1(1.8 \%)$ & 0.114 \\
Headache & $18(31.0 \%)$ & $9(16.4 \%)$ & 0.080 \\
Dizziness & $11(19.0 \%)$ & $5(9.1 \%)$ & 0.179 \\
Weakness & $17(29.3 \%)$ & $5(9.1 \%)$ & 0.009 \\
Rapid pulse & $1(1.7 \%)$ & $2(3.6 \%)$ & 0.612 \\
Increased blood pressure & $3(5.2 \%)$ & $1(1.8 \%)$ & 0.619 \\
Presyncope & $1(1.7 \%)$ & $0(0 \%)$ & 1.000 \\
\hline
\end{tabular}

Abbreviations: CALM-BP, Comprehensive Approach to Lowering Measured Blood Pressure; DASH, Dietary Approach to Stop Hypertension. CALM-BP is based on complementary medicine principles. DASH is according to the US Department of Health and Human Services, National Institute of Health, National Heart, Lung, and Blood Institute.

\section{DISCUSSION}

The study is the first prospective, randomized control clinical trial comparing the effect of a multifactorial approach based on complementary medicine principles (CALM-BP) with the standard DASH and exercise recommended by the US Department of Health and Human Services, National Institute of Health, National Heart, Lung, and Blood Institute. The results of this trial revealed that hypertensive individuals can make comprehensive lifestyle modifications that significantly lower $\mathrm{BP}$, reduce medication usage and improve lipid and blood glucose profile. Not only were participants able to adhere to the demanding CALM-BP programme, but they also reported an increase in their quality of life.

Participants' safety according to the trial protocol required adjustment of medication dosage in cases of prolonged symptomatic hypotension with systolic BP $<110 \mathrm{~mm} \mathrm{Hg}$. Surprisingly, the number of patients experiencing these events was much higher than anticipated (70\% of the participants in the CALM-BP group). Even though antihypertensive medications were reduced or discontinued during the treatment period, the mean $24 \mathrm{~h}$ ambulatory BP at the end of this period was reduced in both groups.

It is difficult to ascertain the major component that reduced BP in the CALM-BP programme. However, as a substantial decrease in BP occurred in early stages of the programme, we assumed that the dietary component had a prominent effect. Furthermore, this effect occurred during the nutritional stage, in which whole grain rice was the major component in the diet, implying that this element had a cardinal effect. Several studies have demonstrated a beneficial effect of whole grains on BP. ${ }^{11,12}$ Studies that examined a rice-diet programme demonstrated significant reduction in $\mathrm{BP}$, weight and cholesterol. ${ }^{13}$ Historically, this method was used by physicians to reduce BP in the early twentieth century. ${ }^{24}$ The mechanism of action by which whole grain rice reduces BP is still not fully understood. In rats, preliminary experimental evidence indicates that a peptide derived by enzymatic hydrolysis of rice dregs has an angiotensin-converting enzyme-like inhibitory effect. ${ }^{25,26}$

It is well documented that weight loss is a major factor contributing to BP reduction. ${ }^{27-29}$ The majority of individuals in the CALM-BP group experienced significant BP reduction during the first weeks of the trial, well before prominent weight loss occurred, suggesting that this was not the main contributing factor to BP reduction. CALM-BP and DASH interventions have distinctly different nutritional elements. The CALM-BP intervention starts with a harsh phase for the first 2-3 weeks in which only whole grain rice and some vegetables are included in the dietary plan. We speculate that these differences account for the rapid decrease in $\mathrm{BP}$ in the initial weeks of the intervention in this group.
$\mathrm{BP}$ reduction or drug dose changes were also demonstrated in other lifestyle modification trials. ${ }^{1-4}$ A significant decrease in BP and weight was demonstrated in the Diet, Exercise and Weight Loss Intervention trial in overweight, hypertensive adults. ${ }^{1}$ However, unlike in the current study that included only nonobese individuals, that reduction did not require step-down or cessation of medication. In the Activity, Diet and Blood Pressure Trial $^{3}$ antihypertensive drugs were withdrawn at the end of a 4-month intervention period if the mean $24 \mathrm{~h}$ ambulatory BP was $<135 / 85 \mathrm{~mm} \mathrm{Hg}$. In the current study, however, it was necessary to reduce medication during the intervention in $70 \%$ of the participants of the CALM-BP group because of a significant systolic $\mathrm{BP}$ reduction of $<110 \mathrm{~mm} \mathrm{Hg}$ accompanied by symptoms of weakness, blurred vision or presyncope. The Non Pharmacological Interventions in the Elderly trial ${ }^{4}$ demonstrated BP reductions, followed by medication withdrawal at the end of the intervention, similar to those observed in the DASH group of the present study.

One may argue that the lower daily sodium intake in the CALMBP diet may have contributed to BP reduction. However, current data suggest that a reduction of $1100 \mathrm{mg}$ in daily sodium intake may reduce systolic and diastolic BP by $3-6$ and $1.5-3 \mathrm{~mm} \mathrm{Hg}$, respectively. ${ }^{30,31}$ Thus, the $800 \mathrm{mg}$ difference in daily sodium intake between the groups cannot explain the magnitude of BP reduction observed in the CALM-BP group.

Several studies have shown that stress management techniques may have significant BP-lowering effect. ${ }^{15,16}$ Schneider et al. ${ }^{16}$ have shown that a stress management programme that utilizes Transcendental Meditation has a beneficial effect in the prevention and control of high BP and may contribute to decreased mortality from cardiovascular diseases in older hypertension population. Other studies have shown that slow and controlled diaphragmatic breathing also has a BP-lowering effect. $^{17,18}$ Yoga and qigong are low-impact cardiovascular exercises that utilize slow diaphragmatic breathing, stretching and relaxation techniques. Small-scale studies demonstrated the positive BP effect of these techniques. ${ }^{19-21}$ We assume that using these techniques in addition to diet and exercise had an additional BP-lowering effect in the CALM-BP group.

The intervention programme resulted in additional benefits likely to improve overall cardiovascular disease risk. These included reductions in fasting blood glucose and cholesterol, and an increase in overall life quality. Participants in the CALM-BP group showed a significant decrease in total cholesterol, low-density lipoprotein cholesterol as well as high-density lipoprotein cholesterol. As physical activity was identical in both intervention groups, we assume that the high-density lipoprotein decrease can be attributed to the nutritional differences between the interventions. The reduction in high-density lipoprotein cholesterol observed in this trial was also reported in other trials featuring low-fat/high-carbohydrate diet. $^{32}$ It is interesting to note that triglycerides also decreased despite the relatively high carbohydrate content of the whole-rice dietary plan, suggesting that this type of complex carbohydrate mitigates the expected rise in triglycerides from a high-carbohydrate diet. No significant effect on the lipid profile was noticed in the DASH group. However, it might be possible that this lack of effect is because of higher percentages $(56 \%)$ of patients treated with cholesterol-lowering drugs at baseline in this group.

Despite the burden of multiple lifestyle modifications and the very demanding rice diet, all the participants in the CALM-BP group completed the 4-month intervention period and the majority of them completed the follow-up period. Although several studies suggested that individuals cannot simultaneously make numerous lifestyle modifications, ${ }^{33,34}$ this trial indicates an opposite notion. Not only did participants adhere to the programme, they reported an increase in quality of life as indicated by SF36 questionnaires. We speculate that the supportive educational and social approach of the programme 
and the group session format, which exposed participants to the positive feedbacks of their fellow colleagues, may have contributed to this finding. In addition, adverse effects were transient and were mostly associated with BP reduction. The high adherence in the CALM-BP group compared with the DASH group after 10 months may be due to the fact that, overall, participants in the CALM-BP group were more satisfied from the intervention as evident from the life quality SF36 questionnaires in which CALM-BP participants scored higher in the emotional section that described their overall feelings regarding life quality.

The study had several limitations. The first is the relatively short duration of the intervention and follow-up period (total of 10 months). A longer follow-up period would allow assessment of long-term outcomes. The second is that home BP levels were recorded by participants and not taken directly from the devices. Even though the compliance of the patients was very high, it might be possible that patients may not have always accurately recorded the obtained readings. The third limitation is that the study employed a parallel randomized controlled design to compare the two interventions, the CALM-BP approach and DASH, both multifactorial interventions, as a whole. Accordingly, it is not possible to evaluate which part of the CALM-BP programme is the most dominant. Moreover, the relatively small study population sample limits the ability to perform subgroup analysis in order to evaluate which patients will benefit the most from such a programme. Longer trial duration and larger population size are therefore required.

Further studies are needed in order to isolate and evaluate which part of the CALM BP programme has the most prominent effect on BP and what subgroup populations will benefit the most from this multifactorial complementary medicine approach.

To conclude, the results of this study highlight the beneficial effect of complementary medicine interventions involving a multifactorial team approach addressing physical, nutritional and psychosocial aspects of hypertension. Implementing lifestyle interventions poses a challenge for both health-care providers and patients; a multifactorial treatment team approach may therefore be warranted.

What is known about this topic?

- Nutritional, physical and psychosocial factors influence blood pressure (BP).

- Intervention such as Dietary Approach to Stop Hypertension (DASH) is at least similar in magnitude to drug therapy.

- Complementary medicine advocates the use of a multifactorial treatment approach to address the varied aspects of hypertension. These measures include a whole-grain rice diet, stress management, controlled diaphragmatic breathing, yoga, qigong and exercise.

What this study adds?

- The study is the first prospective, randomized control clinical study comparing the effect of multifactorial approach, using different aspects of complementary medicine, with the standard Dietary Approach to Stop Hypertension and exercise recommended by the US Department of Health and Human Services, National Institute of Health, National Heart, Lung, and Blood Institute.

- The results of this trial revealed that hypertensive individuals can make comprehensive lifestyle modifications that significantly lower $\mathrm{BP}$, reduce medication usage and improve lipid and blood glucose profile.

- Although the multifactorial programme was very demanding and not easy to perform, patients were able to adhere to it and even reported an increase in their quality of life.

\section{CONFLICT OF INTEREST}

The authors declare no conflict of interest.

\section{ACKNOWLEDGEMENTS}

We thank trial volunteers Shaked Wiemer, Ronit Bar Cochva, Adi Neuman, Guy Ofer, Dana Staerman, Amit Gedalia, Naama Swisa, Efrat Drori, Monique Hasson Elazar, Ziv Meir, Nechama Segal and Shiri Kfir-Ellenbogen for their excellent clinical assistance. We thank Roi Sagi and Shron More for their outstanding administrative and recruitment efforts as well as the staff and nurses of Shiram and Research and Development Units for their expert technical assistance. The study was funded by the research fund of Assaf Harofeh Medical Center.

\section{REFERENCES}

1 Miller ER, Erlinger TP, Young DR, Jehn M, Charleston J, Rhodes D et al. Results of the Diet, Exercise, and Weight Loss Intervention Trial (DEW-IT). Hypertension 2002; 40: 612-618.

2 Appel LJ, Champagne CM, Harsha DW, Cooper LS, Obarzanek E, Elmer PJ et al. Writing Group of the PREMIER Collaborative Research Group. Effects of comprehensive lifestyle modification on blood pressure control: main results of the PREMIER clinical trial. JAMA 2003; 289: 2083-2093.

3 Burke V, Beilin LJ, Cutt HE, Mansour J, Wilson A, Mori TA. Effects of a lifestyle programme on ambulatory blood pressure and drug dosage in treated hypertensive patients: a randomized controlled trial. J Hypertens 2005; 23: 1241-1249.

4 Whelton PK, Appel LJ, Espeland MA, Applegate WB, Ettinger Jr WH, Kostis JB et al. Sodium reduction and weight loss in the treatment of hypertension in older persons: a randomized controlled trial of nonpharmacologic interventions in the elderly (TONE). TONE Collaborative Research Group. JAMA 1998; 279: 839-846.

5 Appel LJ. American Society of Hypertension Writing Group. ASH position paper: dietary approaches to lower blood pressure. J Am Soc Hypertens 2010; 4: 79-89.

6 Sacks FM, Svetkey LP, Vollmer WM, Appel LJ, Bray GA, Harsha D et al. for the DASHSodium Collaborative Research Group. Effects on blood pressure of reduced dietary sodium and the Dietary Approaches to Stop Hypertension (DASH) diet: DASHSodium Collaborative Research Group. N Engl J Med 2001; 344: 3-10.

7 Dickinson HO, Mason JM, Nicolson DJ, Campbell F, Beyer FR, Cook JV et al. Lifestyle interventions to reduce raised blood pressure: a systematic review of randomized controlled trials. J Hypertens 2006; 24: 215-233.

8 Lucini D, Di Fede G, Parati G, Pagani M. Impact of chronic psychosocial stress on autonomic cardiovascular regulation in otherwise healthy subjects. Hypertension 2005; 46: 1201-1206.

9 Chobanian AV, Bakris GL, Black HR, Cushman WC, Green LA, Izzo JL et al. and the National High Blood Pressure Education Program Coordinating Committee. Seventh Report of the Joint National Committee on Prevention, Detection, Evaluation, and Treatment of High Blood Pressure. Hypertension 2003; 42: 1206-1252.

10 Appel LJ, Moore TJ, Obarzanek E, Vollmer WM, Svetkey LP, Sacks FM et al. A clinical trial of the effects of dietary patterns on blood pressure. $N$ Engl J Med 1997; 336: 1117-1124.

11 Wang L, Gaziano JM, Liu S, Manson JE, Buring JE, Sesso HD. Whole- and refinedgrain intakes and the risk of hypertension in women. Am J Clin Nutr 2007; 86: 472-479.

12 Behall KM, Scholfield DJ, Hallfrisch J. Whole-grain diets reduce blood pressure in mildly hypercholesterolemic men and women. J Am Diet Assoc 2006; 106: 1445-1449.

13 Ard J, Rosati R, Oddone E. Culturally-sensitive weight loss program produces significant reduction in weight, blood pressure, and cholesterol in eight weeks. J Natl Med Assoc 2000; 92: 515-523.

14 Kempner W, Newborg BC, Peschel RL, Skyler JS. Treatment of massive obesity with rice reduction diet program. An analysis of 106 patients with at least a $45-\mathrm{kg}$ weight loss. Arch Intern Med 1975; 135: 1575-1584.

15 Schneider RH, Alexander CN, Staggers F, Rainforth M, Salerno JW, Hartz A et al. Long-term effects of stress reduction on mortality in persons $>$ or $=55$ years of age with systemic hypertension. Am J Cardiol 2005; 95: 10601064.

16 Schneider RH, Alexander CN, Staggers F, Orme-Johnson DW, Rainforth M, Salerno $\mathrm{JW}$ et al. A randomized controlled trial of stress reduction in African Americans treated for hypertension for over one year. Am J Hypertens 2005; 18: 88-98.

17 Joseph CN, Porta C, Casucci G, Casiraghi N, Maffeis M, Rossi M et al. Slow breathing improves arterial baroreflex sensitivity and decreases blood pressure in essential hypertension. Hypertension 2005; 46: 714-718.

18 Grossman E, Grossman A, Schein MH, Zimlichman R, Gavish B. Breathing-control lowers blood pressure. J Hum Hypertens 2001; 15: 263-269.

19 Cheung BM, Lo JL, Fong DY, Chan MY, Wong SH, Wong VC et al. Randomized controlled trial of qigong in the treatment of mild essential hypertension. $J$ Hum Hypertens 2005; 19: 697-704.

20 Lee MS, Pittler MH, Guo R, Ernst E. Qigong for hypertension: a systematic review of randomized clinical trials. J Hypertens 2007; 25: 1525-1532.

21 Mamtani R, Mamtani R. Ayurveda and yoga in cardiovascular diseases. Cardiol Rev 2005; 13: 155-162. 
22 Crispin J, Coulter A, Wright L. Short form 36 (SF 36) health survey questionnaire: normative data for adults of working age. BMJ 1993; 306: 143740.

23 Lower your Blood Pressure with DASH Eating Plan. U.S. DHSS, National Institute of Health, National Heart, Lung, and Blood Institute 2006, (https://www. nhlbi.nih.gov/health/public/heart/hbp/dash/new_dash.pdf).

24 Cirillo M, Del Giudice L, Bilancio G, Franzese MD, De Santo NG. Low salt diet and treatment of hypertension: an old story. J Nephrol 2009; 14: 136-138.

25 Chen Q, Xuan G, Fu M, He G, Wang W, Zhang H et al. Effect of angiotensin l-converting enzyme inhibitory peptide from rice dregs protein on antihypertensive activity in spontaneously hypertensive rats. Asia Pac J Clin Nutr 2007; 16: 281-285.

26 Li GH, Qu MR, Wan JZ, You JM. Antihypertensive effect of rice protein hydrolysate with in vitro angiotensin I-converting enzyme inhibitory activity in spontaneously hypertensive rats. Asia Pac J Clin Nutr 2007; 16: 275-280.

27 Neter JE, Stam BE, Kok FJ, Grobbee DE, Geleijnse JM. Influence of weight reduction on blood pressure: a meta-analysis of randomized controlled trials. Hypertension 2008; 42: 878-884.

28 Williamson DF. Intentional weight loss: patterns in the general population and it association with morbidity and mortality. Int J Obes 1997; 21: 14-21.

29 Aucott L, Rothnie H, McIntyre L, Thapa M, Waweru C, Gray D. Long-term weight loss from lifestyle intervention. Benefits blood pressure? A systematic review. Hypertension 2009; 54: 756-762.
30 Sacks FM, Svetkey LP, Vollmer WM, Appel LJ, Bray GA, Harsha D et al. DASHSodium Collaborative Research Group. Effects on blood pressure of reduced dietary sodium and the Dietary Approaches to Stop Hypertension (DASH) diet. N Engl J Med 2001; 344: 3-10.

31 Horacio JA, Nicolaos EM. Sodium and potassium in the pathogenesis of hypertension. N Engl J Med 2007; 356: 1966-1978.

32 Kris-Etherton PM, Pearson TA, Wan Y, Hargrove RL, Moriarty K, Fishell V et al. High-monounsaturated fatty acid diets lower both plasma cholesterol and triacylglycerol concentrations. Am J Clin Nutr 1999; 70: 1009-1015.

33 Blaufox MD, Langford HG, Oberman A, Hawkins CM, Wassertheil-Smoller SW Cutter GR. Effect of dietary change on the return of hypertension after withdrawal of prolonged antihypertensive therapy (DISH). Dietary Intervention Study of Hypertension. J Hypertens Suppl 1984; 2: 179-181.

34 Effects of weight loss and sodium reduction intervention on blood pressure and hypertension incidence in overweight people with high-normal blood pressure. The Trials of Hypertension Prevention phase II. The Trials of Hypertension Prevention Collaborative Research Group. Arch Intern Med 1997; 157: 657-667.

cC)(-) $\odot$ This work is licensed under a Creative Commons Attribution NonCommercial-NoDerivs 3.0 Unported License. To view a copy of this license, visit http://creativecommons.org/licenses/by-nc-nd/3.0/ 